\title{
An Overview on Stability of Extemporaneously Prepared Pharmaceutical Suspension
}

Naveed S*, Akhtar F and Khan S

Faculty of Pharmacy, Jinnah University for Women, Karachi, Pakistan

\begin{abstract}
Aim: The aim of this study was to write review on stability studies of extemporaneous preparations.

Materials and methods: Different methods are used for checking stability studies, depending on the nature of the preparations, like visual inspection, $\mathrm{pH}$ checking, different temperature storage, and HPLC.

Results: It was found that the stability concern with the pharmaceutical suspensions includes the variation in both physical and chemical properties. Therefore, it is most important that formulator must ensure the efficacy of the formulation throughout the shelf life period. In this review article, method used for stability checking is valid and up to mark, so patient can use these extemporaneous preparations according to recommended period of time.

Conclusion: We can conclude of our Stress studies that these suspensions cannot be stored over long period of time (average 90-120 days); but they are stable below 120 days (depending on the preparation) so we can have used these preparations because there is no stability issue if used in within recommended time-period, undeniably extemporaneously prepared suspensions can be a helpful for pediatric, geriatric and unconscious patients in drug dosing.
\end{abstract}

Keywords: Suspension; Stability studies; Extemporaneous preparation

\section{Introduction}

Suspensions are one of the most significant pharmaceutical dosage forms that are widely acceptable of poorly soluble drugs with different therapeutic purpose. They are intended to be use for making tropical, parental, otic, ophthalmic and oral dosage forms [1]. They are disperse system by means of 2 phases; one is particulate matter (dispersed phase) and the second is continuous medium (dispersion medium).

Suspensions are the heterogeneous system with a uniform dispersion in which solid drug particles with minimum solubility are suspended within the vehicle [2].

The particle size of the drug mainly depends upon the physiochemical properties and rheological characteristics; thus, it may vary from one formulation to another. The classification of disperse system depends upon the particle size of the drug. For example, suspensions with the particle size between 0.1-0.2 $\mu$ are considered as colloidal suspensions. Most of the pharmaceutical suspensions are coarse suspensions, and their particle size is in between 1-100 $\mu \mathrm{m}$. All the suspensions separate on standing. For the formulator, it is one of the main concerns is to permit easy resuspendibilty of settled particulate matter but also to decrease the sedimentation rate [3].

\section{Qualities of an ideal suspension}

a. The particles in disperse phase should not be readily settled down and redisperse on shaking.

b. There should be no cake formation on settled particles.

c. The suspension should be free from grittiness (for tropical use).

d. It should be chemically and physically stable.

\section{Applications of pharmaceutical suspensions}

a. To mask the bitter taste of the drug.

b. For those drugs which are not stable in aqueous solutions, insoluble derivatives or non-aqueous vehicles can be used, for such drugs are formulated as suspensions.

c. Insoluble drugs which must be given in oral liquid dosage form (children, elder patients), suspensions are best choice.

d. Can be used as multipurpose having diverse routes of administrations like oral, parental and tropical.

e. Those drugs which are not stable in dispersion medium for longer period of time, to reduce the contact time between the drug particles and dispersion medium, reconstitute powders are formulated as suspensions [4].

The stability concern with the pharmaceutical suspensions includes the variation in both physical and chemical properties. The troubles associated with suspension preparations are caking, change in $\mathrm{pH}$ and color, crystal growth, microbial growth, rapid settling of the particles, microbial growth and decrease drug potency. Therefore, the formulator must ensure the efficacy of the formulation throughout the shelf life period.

Different methods have been reported to study the stability of suspensions, among which $\mathrm{pH}$, color change (visual appearance) and the chemical degradation of the drug formulations are to be studied at different temperatures usually at $4^{\circ} \mathrm{C}$ and $22^{\circ} \mathrm{C}$ with different time intervals. Stability studies also conducted on the suspensions which

*Corresponding author: Naveed S, Faculty of Pharmacy, Jinnah University fo Women, Karachi, Pakistan, Tel: +0092-03002621917; Fax: +0092-36440171; E-mail: safila117@yahoo.com

Received Jan 21, 2017; Accepted June 09, 2017; Published June 19, 2017

Citation: Naveed S, Akhtar F, Khan S (2017) An Overview on Stability of Extemporaneously Prepared Pharmaceutical Suspension. J Bioequiv Availab 9: 452-454. doi: $10.4172 / \mathrm{jbb} .1000343$

Copyright: ( 2017 Naveed S, et al. This is an open-access article distributed under the terms of the Creative Commons Attribution License, which permits unrestricted use, distribution, and reproduction in any medium, provided the original author and source are credited. 
are extemporaneously prepared and to be dispensed to those patients which are unable to take oral dosage forms such as pediatric or geriatric patients. Stability of extemporaneously prepared suspensions are critically analyzed not only its microbial integrity but also the choice of ingredients which do not interact with the active pharmaceutical agent [5]. Here we discuss some extemporaneously prepared suspensions and their respective stability studies.

Aim of study: The aim of this study was to write review on stability studies of extemporaneous preparations. Here we example different preparation that was extemporaneous prepared and observe that either stability studies of these preparations are up to the mark and they are stable for recommended time-period.

\section{Materials and Methods}

In this review article, we used different material and method for different suspension stability checking. Like for Cyclophosamide suspension used HPLC for its chemical, microbial and stability studies. For Sinitinib suspension that is prepared by capsules, stability study was conducted by under refrigeration $\left(4^{\circ} \mathrm{C}\right)$ and at room temperature. For Rufinamide oral suspension, this suspension was placed in ambered plastic bottles in room temperature for 90 days. After 90 days, the sample was analyzed using HPLC. For Clozapine suspension with different suspending mediums was stored at $23^{\circ} \mathrm{C}$ for 63 days. Samples were taken after 63 days and analyzed using R-HPLC technique. For oral suspension of Lanzoprazole and Omeprazole, the suspensions of both drugs were stored in amber colored plastic oral syringes. These syringes were stored at 2 different temperatures i.e., $22^{\circ} \mathrm{C}$ and $4^{\circ} \mathrm{C}$ for 60 days. After 60 days sample were analyzed by HPLC method. For Moxifloxacin Oral suspension, this suspension was stored in amber plastic bottles at room temperature. Samples were analyzed with different time interval up to 90 days HPLC technique. For Celecoxib oral suspension, the suspension was stored at any of these two temperatures i.e., $5^{\circ} \mathrm{C}$ or $23^{\circ} \mathrm{C}$ in polyvinyl chloride bottles for 93 days. After 93 days Sample was analyzed at different time intervals by using HPLC. For Propylthiouracil suspension was stored at two different temperatures i.e., $4^{\circ} \mathrm{C}$ and $25^{\circ} \mathrm{C}$ up to 91 days. After 91 days, the suspension was analyzed. For Gylcopyrolate suspension was stored at $23-25^{\circ} \mathrm{C}$ and analyzed at different time interval using HPLC. Flavor, microbial and visual inspection was also done. For Amlodipine besylate suspension was stored in plastic dispensing bottles at $4^{\circ} \mathrm{C}$ and $25^{\circ} \mathrm{C}$. The samples were examined using HPLC at different time interval up to 91 days. For Lisinopril suspension was prepared and analyzed up to 6 weeks at $25^{\circ} \mathrm{C}$. For tiagabine hydrochloride suspensions were stored at $4^{\circ} \mathrm{C}$ and $25^{\circ} \mathrm{C}$. The formulations were stored up to 91 days and the samples were analyzed by HPLC. Spironoloactone suspension stored in amber glass bottles at $4^{\circ} \mathrm{C}$ and $2^{\circ} \mathrm{C}$ for three months. The samples were withdrawn at different time-period and analyzed by HPLC. Lamotrigine suspensions were stored at $4^{\circ} \mathrm{C}$ and $25^{\circ} \mathrm{C}$. These Samples were collected at different duration of time and analyzed in terms of physical and chemical inspection. Terbinafine suspension was stored in amber polyethylene bottle and examined at $4^{\circ} \mathrm{C}$ and $25^{\circ} \mathrm{C}$ for 90 days.

\section{Results}

The results of all extemporaneous preparation which we used for review are as follows:

\section{Cyclophosphamide suspension}

Kennedy, R. extemporaneously prepared an oral suspension of cyclophosphamide in aqueous and methyl-cellulose based medium (Ora-Plus) and analyzed its chemical, microbial and physical stability studies for 56 days at the temperature of $4^{\circ} \mathrm{C}$ and $22^{\circ} \mathrm{C}$ using HPLC-UV method. The results found satisfied for both simple syrup and in Oraplus concluding the shelf life of the prepared suspensions 8 and 3 days, respectively [6].

\section{Sinitinib suspension prepared by capsules}

Another anti-cancerous drug Sunitinib was extemporaneously prepared from capsules and his associates as no pediatric preparations was commercially available and studied its stability under refrigeration $\left(4^{\circ} \mathrm{C}\right)$ and at room temperature. The result showed the satisfied outcome at both the temperature. The study was conducted for 60 days and both physically and chemically, no changes were found in the formulation [7].

\section{Rufinamide oral suspension}

Successfully prepared an antiepileptic drug Rufinamide which was unavailable in liquid dosage form for treatment of generalized seizures. Using $400 \mathrm{mg}$ tablet an extemporaneous suspension was prepared in both sugar and non-sugar (sugar free) in $60 \mathrm{ml}$ of Ora-plus and Orasweet used for sugar containing suspensions. For sugar, free Ora-sweet SF was used. In ambered plastic bottles the suspension was placed in room temperature for 90 days. The sample was analyzed using HPLC at different time interval $(14,28,56$, and 90 days). Results revealed that the drug showed up to $90 \%$ stability at $90^{\text {th }}$ day in both the preparations and there were significant physical or chemical changes were observed neither any microbial growth was detected [8].

\section{Clozapine suspension with different suspending mediums}

6 different suspending vehicles was used to prepare 6 clozapine suspensions including Ora-plus, Ora-sweet, simple syrup, vehicle used by hospital for sick children, Guy's pediatric mixture and 1:1 ratio of Ora-plus and Ora-sweet. $100 \mathrm{ml}$ of suspension was prepared containing $20 \mathrm{mg} / \mathrm{ml}$ clozapine, stored at $23^{\circ} \mathrm{C}$ for 63 days. Samples were taken at 0 , $3,6,14,28$ and 63 days and analyzed using R-HPLC technique. Almost $95 \%$ was remained unchanged at $63^{\text {th }}$ day despite the consequences of suspending vehicle [9].

\section{Preparation of oral suspension of Lanzoprazole and Omeprazole}

Using the contents of lanzoprazole and omeprazole capsules, extemporaneous suspensions was prepared using $8.4 \%$ sodium bicarbonate as a suspending medium having concentration of 3 and 2 $\mathrm{mg} / \mathrm{ml}$ respectively. The suspensions of both drugs were stored in amber colored plastic oral syringes. The syringes were stored at 2 different temperatures i.e., $22^{\circ} \mathrm{C}$ and $4^{\circ} \mathrm{C}$ for 60 days. The samples were taken from syringes at different time interval and were analyzed by HPLC method. The results revealed that at ambient temperature Omeprazole and lanzoprazole showed less stability (14 days and $8 \mathrm{~h}$ respectively) as compare to refrigerated storage condition (14 days) [10].

\section{Moxifloxacin oral suspension}

A $20 \mathrm{mg} / \mathrm{ml}$ oral suspension of moxifloxacin was prepared using $400 \mathrm{mg}$ and $30 \mathrm{ml}$ of Ora-Plus and Ora-plus sweet/SF. The suspension was stored in amber plastic bottles at room temperature. Samples were analyzed with different time interval up to 90 days HPLC technique. More than $90 \%$ of the drug was retained up to 90 days and there was no significant physically nor chemically was change observed in the preparation [11]. 
Citation: Naveed S, Akhtar F, Khan S (2017) An Overview on Stability of Extemporaneously Prepared Pharmaceutical Suspension. J Bioequiv Availab 9: 452-454. doi: 10.4172/jbb.1000343

\section{Celecoxib oral suspension}

A $10 \mathrm{mg} / \mathrm{ml}$ Celecoxib suspension was prepared using single capsule using flavoring agent and Ora-blend as a suspending vehicle. The preparation was stored at either $5^{\circ} \mathrm{C}$ or $23^{\circ} \mathrm{C}$ in Polyvinyl Chloride bottles (PVC) for 93 days. Sample was analyzed by HPLC at different time intervals. Results revealed a 3-month expiry of the prepared suspension can be safely set up in either any of case of temperature. No physical neither chemical changes were observed during the analyzing period [12].

\section{Gylcopyrolate suspension}

Glycopyrolate is used to treat peptic ulcers. Using $1 \mathrm{mg}$ tablet, 30 tablets was ground to prepare $0.5 \mathrm{mg} / \mathrm{ml}$ extemporaneous suspension using Ora-plus and Ora-sweet or Ora-sweet SF as a suspending agent. The prepared suspension was stored at $23-25^{\circ} \mathrm{C}$ and analyzed at $0,7,15,30,60$ and 90 days at HPLC. Flavor, microbial and visual inspection was also done and results showed the $95 \%$ of the drug concentration was retained at 90 -day [13].

\section{Amlodipine besylate suspension}

An extemporaneous suspension of amlodipine besylate was prepared for those patients who are not able to swallow the tablets, using ORA-plus/Ora-sweet (1:1) and 1\% methylcellulose syrup and stored in 10 plastic dispensing bottles at $4^{\circ} \mathrm{C}$ and $25^{\circ} \mathrm{C}$. The samples were examined using HPLC at different time interval up to 91 days. No detectable change was observed in the prepared suspensions. The suspension showed more stability at $4^{\circ} \mathrm{C}$ than $25^{\circ} \mathrm{C}$ (91 days and 56 days respectively) [14].

\section{Lisinopril suspension}

Oral suspension of lisinopril was prepared using $20 \mathrm{mg}$ commercially available tablets and also studied its photo stability as per ICH guidelines. $1 \mathrm{mg} / \mathrm{ml}$ suspension was prepared and analyzed up to 6 weeks at $25^{\circ} \mathrm{C}$. Ora-sweet SF and Bicitra were used as a suspending vehicle. The preparation showed maximum physical, chemical and microbial stability for 6 weeks at $25^{\circ} \mathrm{C}$ and $35 \%$ relative humidity [15].

\section{Discussion}

In this review article, we overviewed different extemporaneously prepared pharmaceutical suspension and check their stability methods. The stability concern with the pharmaceutical suspensions includes the variation in both physical and chemical properties. The troubles associated with suspension preparations are caking, change in $\mathrm{pH}$ and color, crystal growth, microbial growth, rapid settling of the particles, microbial growth and decrease drug potency. Therefore, the formulator must ensure the efficacy of the formulation throughout the shelf life period. According to type of suspensions methods are used for checking their stability. Temperature variation is applying and then checks the stability. Visual inspection, $\mathrm{pH}$ changes, and high-performance liquid chromatography technique are used for checking stability. All results are satisfactory and valid and patient can used these preparations according to recommended period of time.

\section{Conclusion}

Listed above the literature studies we can conclude that extemporaneous suspensions can be formulated for those pharmaceuticals products whose suspensions are not available using various suspending vehicles. Stress studies of these suspensions revealed that these suspensions cannot be stored over long period of time (average 90-120 days); but they are stable below 120 days (depending on the preparation) so we can have used these preparations because there is no stability issue if used in within recommended time-period indeed extemporaneously prepared suspensions can be a helpful for pediatric, geriatric and unconscious patients in drug dosing.

\section{References}

1. Bayindir ZS, Antep MN, Yukse N (2015) Development and characterization of mixed niosomes for oral delivery using candesartan cilexetil as a model poorly water-soluble drug. AAPS PharmSciTech 16: 108-117.

2. Muhammad KW, Akthar N, Bakhsh S, Caldeira EJ, Khan B (2015) Skin lightening and sebum control efficacy of a cosmetic emulsion containing extract of tamarind seeds on asian skin type. Latin Am J Pharm 34: 570-575.

3. Hasegawa Y, Higashi K, Yamamoto K, Moribe K (2015) Direct evaluation of molecular states of Piroxicam/poloxamer nanosuspension by suspended-state NMR and Raman spectroscopies. Mol Pharmaceut 12: 1564-1572.

4. Campbell GA, Vallejo E (2015) Primary packaging considerations in developing medicines for children: oral liquid and powder for constitution. J Pharmaceut Sci 104: 52-62.

5. Guo Z, Yin X, Liu C, Wu L, Zhu W (2016) Microstructural investigation using synchrotron radiation $\mathrm{x}$-ray microtomography reveals taste-masking mechanism of acetaminophen microspheres. Int J Pharm 499: 47-57.

6. Kateb NE, Chaussard M, Bellenger P, Petit A, Faure P, et al. (2015) Stability of an extemporaneously prepared bleomycin-lidocaine-epinephrine intradermal admixture used in dermatology. J Oncol Pharma Pract 21: 178-187.

7. Bedouet L, Verret V, Louguet S, Servais E, Pascale F, et al. (2015) Anti-angiogenic drug delivery from hydrophilic resorbable embolization microspheres: an in vitro study with sunitinib and bevacizumab. Int J Pharm 484: 218-227.

8. Batchelor HK, Marriott JF (2015) Formulations for children: problems and solutions. Br J Clin Pharmacol 79: 405-418.

9. Gaspar DP, Faria V, Gonçalves LM, Taboada P, Remuñán-López C, et al (2016) Rifabutin-loaded solid lipid nanoparticles for inhaled antitubercular therapy: physicochemical and in vitro studies. Int J Pharm 497: 199-209.

10. Glass BD, Haywood A (2015) Stability considerations in liquid dosage forms extemporaneously prepared from commercially available products.

11. Barrera CM, Mykietiuk A, Metev H, Nitu MF, Karimjee N, et al. (2016) Efficacy and safety of oral solithromycin versus oral moxifloxacin for treatment of community-acquired bacterial pneumonia: a global, double-blind, multicentre, randomised, active-controlled, non-inferiority trial (SOLITAIRE-ORAL). Lancet Infect Dis 16: 421-430.

12. Fong SYK, Martins SM, Brandl M, Bauer-Brandl A (2016) Solid phospholipid dispersions for oral delivery of poorly soluble drugs: investigation into celecoxib incorporation and solubility-in vitro permeability enhancement. J Pharm Sci 105: 1113-1123.

13. Imbimbo BP, Chain D (2015) Formulations and methods of treating alzheimer's disease and other proteinopathies by combination therapy. US Patent Application No. 14/707,033.

14. Ferreira AO, Polonini HC, Silva SL, Patrício FB, Brandão MAF, et al. (2016) Feasibility of amlodipine besylate, chloroquine phosphate, dapsone, phenytoin, pyridoxine hydrochloride, sulfadiazine, sulfasalazine, tetracycline hydrochloride, trimethoprim and zonisamide in SyrSpend ${ }^{\circledR}$ SF PH4 oral suspensions. J Pharm Biomed Anal 118: 105-112.

15. Lewis DA, Keeble CA, Church T (2015) Suspension formulations. Google Patents. 